\title{
El trabajo social «judío»y su contribución a la configuración del Trabajo Social general como profesión y disciplina. Una primera aproximación científico-filosófica
}

\author{
«Jewish» social work and its contribution to the general Social Work setting \\ as a profession and discipline. A first scientific-philosophical approach
}

\author{
Alfredo Hidalgo Lavié \\ Universidad Nacional de Educación a Distancia \\ ahidalgo@der.med.es
}

Recibido: 08/08/2013

Revisado: $16 / 01 / 2014$

Aceptado: 17/03/2014

Disponible on line: $27 / 06 / 2014$

\section{Resumen}

Los orígenes del Trabajo Social tradicionalmente se han vinculado, fuera de nuestras fronteras, con el pensamiento protestante. La diversidad de corrientes cristianas en particular y de confesiones religiosas en general constituye una seña de identidad específicamente americana. La religión no es sólo una concepción de la vida que determina pautas de comportamiento, también es una forma de pensar, cuyo procedimiento puede o no puede permitir la innovación y la creatividad, además de la explicación. La influencia del pensamiento judío en el devenir del Trabajo Social invita a abordar esta cuestión diletante: ¿por qué el Trabajo Social pre-profesional se desarrolló de ese modo?

Palabras clave: Trabajo Social judío, servicio social, método profesional, caridad, responsabilidad pública.

\begin{abstract}
The origins of social work have traditionally been linked, outside our borders, with Protestant thought. The diversity of Christian denominations in particular and religious groups in general is a sign of American identity. Religion is not just a view of life that determines patterns of behavior, it is also a way of thinking and its process may or may not allow for innovation and creativity, as well their explanation. The influence of Jewish thought on the future of Social work invites to approach this dilettante question: why is the pre-professional Social work developed that way?

Keywords: Jewish social work, social service, professional approach, charity, public responsibility.

Referencia normalizada: Hidalgo Lavié, A. (2014): «El trabajo social “judío” y su contribución a la configuración del Trabajo Social general como profesión y disciplina. Una primera aproximación científico-filosófica». Cuadernos de Trabajo Social, 27(1): 187-195.
\end{abstract}

Sumario: Introducción. 1. Las razones históricas de un trabajo social específicamente «judío». 2. Personas, hechos y testimonios. La acción social judía en el germen del Trabajo Social. 3. El New Deal y la emergencia de la responsabilidad pública. El comienzo del fin del Trabajo Social judío. 4. Conclusiones. 5. Referencias bibliográficas.

\section{Introducción ${ }^{1}$}

Con motivo de la renovación obligada de los manuales básicos que sirven de instrumentos para el proceso de aprendizaje de nuestros estudiantes de Grado en Trabajo Social, en el marco de los principios y directrices marcadas por la Declaración de Bolonia, se presentó la ocasión de hacer un análisis comparado de la historia y del ejercicio de la profesión de la mano de una selección de países. En este texto, y gracias a la participación de profesionales de la intervención directa de diferentes nacio-

${ }^{1}$ Todas las citas directas en español son del autor de este artículo. 
nes, se obtiene como primera lección que la conformación de la disciplina y de la profesión posee una inevitable impronta nacional, afectada por las variables de la historia política del país en análisis, su estructura social, su desarrollo económico, sus valores culturales, etc. Una impronta que, a su vez y como no puede ser de otro modo, se ve influenciada decisivamente por los acontecimientos internacionales. La cuestión política, en sentido extenso, es preciso conocerla si se quiere aprehender, con amplitud de miras, el proceso de formación histórica de las disciplinas, incluida la nuestra.

Los orígenes del Trabajo Social son anglosajones, y muy particularmente, estadounidenses. Una suerte del destino, si se permite la expresión, porque sólo en una sociedad libre y plural que garantiza los derechos de las minorías puede emerger la libertad de pensamiento, de la crítica y de la creatividad ${ }^{2}$.

En las siguientes páginas se pretende explicar que el origen religioso, y ulterior desarrollo de la acción social americana que se ha venido conociendo como la génesis del Trabajo Social pre-profesional, posee un origen, cuando menos, no exclusivamente protestante. La contribución de profesionales judíos de la intervención y de la enseñanza, muchos de ellos mujeres, lejos de monopolizar en exclusiva el conjunto de todo este proceso histórico de la profesión, fue decisiva. El conocimiento de esta realidad nos permitirá comprender, con mayor claridad, por qué el Trabajo Social se asienta sobre unas bases profundamente humanistas, primero, y busca en el método científico, después, la idoneidad del procedimiento para la intervención profesional.

Con este fin, el artículo se estructura en tres apartados. Se inicia explicando las razones históricas por las cuales la intervención profesional con comunidades y grupos posee una dilatada experiencia en las comunidades judías. Estas razones históricas poseen unas razones políticas, sociales y económicas que explican, en parte, la utilización por muchos de los autores, citados en las fuentes, de la denominación «judío». El epígrafe siguiente se focaliza en la visibilidad de toda esta experiencia, tanto a nivel organizativo como formativo, y como parte activa en el debate apasionante de la época sobre el carácter profesional o no del Trabajo Social incipiente. Por último, en su epígrafe 3, se analiza cómo la emergencia de un intensivo intervencionismo público aúna la diversidad de interpretaciones sobre el ejercicio y la metodología de la profesión en torno a principios más comunes, por encima de las diferentes concepciones de las corrientes religiosas.

\section{Las razones históricas de un trabajo so- cial específicamente «judío»}

«Si Trabajo Social es en sí mismo difícil de definir, el término Trabajo Social Judío añade una nueva dimensión de perplejidad, abordando cuestiones que han sido debatidas en la comunidad judía por más de medio siglo», afirmó Herman D. Stein en 1958. Este enunciado pasaría quizá a formar parte del anecdotario inmenso de la historia y del debate sobre la identidad del Trabajo Social, si no fuera porque es producto, nada menos, que de la defensa de la tesis doctoral del mencionado autor (p.4).

Esta perplejidad será, sin duda, aún mayor para aquellos que, de modo insuficiente, han prestado poco interés y atención a los orígenes de la profesión y de la disciplina. Mucho mayor si se añade la escasa o inexistente proximidad hacia la literatura estadounidense al respecto. Pues una primera sorpresa en esta aproximación es el descubrimiento de la copiosa literatura al respecto en el país de Mary Richmond.

Importante es, a este respecto, el esfuerzo de Paz Méndez-Bonito (2011) en su artículo publicado en Cuadernos de Trabajo Social al cuestionarse abiertamente sobre las corrientes sociales que formaron la ética del pensamiento de la gran reconocida pionera. Sobresaliente es, entre otros enunciados, el siguiente:

Otro fenómeno demográfico que marca el tiempo histórico [de la autora] es la ya mencionada masiva inmigración de Europa. A la masa de inmigrantes procedentes de una Irlanda pauperizada, hambrienta y católica, le sigue la se-

${ }^{2}$ Yugoslavia fue el único país comunista de la posguerra en el que se permitió crear varias escuelas de Trabajo Social. Habrá que esperar al desfondamiento de la U.R.S.S. y a la crisis del comunismo de la década de 1990 para que en los países de la Europa del Este florezcan los centros de formación educativa en Trabajo Social (Lyons, Hokenstad, Pawar, Huegler y Hallet, 2012). 
gunda gran inmigración de países de fuera de la influencia británica (Italia, Polonia, Alemania y Rusia) y fuera de la esfera protestante (católicos, judíos y ortodoxos). La necesidad de americanizar a los 25 millones de la mayoría de los recién llegados se hace patente (p. 27).

Estos nuevos inmigrantes a los que hace alusión llegaron a los Estados Unidos entre la Guerra Civil americana (1861-1865) y la irrupción de la Primera Guerra Mundial (1914). Durante la primera década del siglo $\mathrm{XX}$, un tercio de la población de las principales ciudades era de origen extranjero y en Nueva York o Chicago más del 50 por ciento estaba compuesto por inmigrantes. Esta oleada masiva no siempre fue del todo bien recibida y fue, como consecuencia, motivo de grandes preocupaciones que «reflejaban claros y amplios prejuicios anti-urbanos y anti-europeos, particularmente contra católicos y judíos (...)» (Reisch, 1998, p. 163). En este contexto, señala el mismo autor, es en el que la profesionalización comienza su andadura con el primer programa especializado para el ejercicio profesional en la comunidad judía, organizado por la New York Kehillah y que funcionó durante los años 1916-1919. Años más tarde, se creó la Graduate School for Jewish Social Work, que estuvo operativa entre 1925 y 1939. Sin duda alguna, la contribución a la educación profesional, reconoce Lynne M. Healy (2001), es la piedra clave del establecimiento de la profesión. A este respecto, es preciso recordar la labor de otra reconocida pionera, Alice Salomon, que comenzó en 1899 el primer curso práctico para mujeres jóvenes interesadas en Trabajo Social, fundó la primera escuela de Trabajo Social en Berlín en 1908, y que por su origen judío tuvo que emigrar décadas más tarde a Nueva York, perseguida por la Gestapo. También Manon Luttichau, pionera de la profesionalización en Dinamarca, cuyos viajes a los Unidos entre 1922 y 1932 contribuyeron sin duda a su impulso por la creación de la Social School en 1937 en Dinamarca y por la fundación, un año más tarde, de la National Association of Social Work en dicho país. Mujeres, en suma, cuya vinculación con América en particular, pero cuya vocación internacional por el intercambio de ideas y experiencias fue decisiva para sus aportaciones propias a la consoli- dación de los esfuerzos en pro de la profesión. En relación a Manon Luttichau, Lynne M. Healy apunta: «estaba convencida de que ningún trabajador social puede quedarse sentado (exclusivamente) en su propio país para propiciar el desarrollo del Trabajo Social, sino que debe visitar otros lugares para intercambiar experiencias» (p. 26).

Este componente judío en programas de la educación profesional, que hace referencia al conocimiento del estilo de vida, costumbres, ceremonias, rituales religiosos, es intrínseco a la dilatada experiencia de vida comunitaria de este colectivo social diferenciado, por lo que las habilidades y destrezas para comunicar y trabajar con la comunidad encuentra, particularmente, en las comunidades judías, por su propia historia, unas raíces ancestrales. La solidaridad, el apoyo mutuo, la cooperación, si bien se nutren de preceptos religiosos que se abordarán a continuación, encuentran igualmente su razón de ser en la necesidad de autoprotección de esta minoría social perseguida a lo largo de toda la historia. A este respecto, las palabras de Morris Zelditch (1947) justifican este planteamiento:

En términos generales, puede afirmarse que la labor de las agencias sociales judías no difiere de aquellas otras que intervienen igualmente en el campo de lo social (...). Pero, ¿posee la agencia judía alguna responsabilidad añadida por las condiciones específicas que afectan a los judíos? Debido a que las agencias operan en el seno de la comunidad judía, su actividad se ve influenciada por los problemas (específicos) de la comunidad judía. (p. 19).

Asimismo, como reconoce el doctor Herman D. Stein (1958), «para los judíos convertirse en una carga para la sociedad no judía era algo inconcebible» (p. 11). No sólo porque se tratara ya de una práctica religiosa propia de las comunidades judías, sino, como se ha comentado, por la imperiosa necesidad de autoprotección y de ayuda mutua.

Ciertamente, el concepto de comunidad en general y particularmente la idea del socorro, del auxilio al necesitado constituyen un pivote nuclear del pensamiento filosófico-religioso del judaísmo. Esta fuerte tradición filantrópica trasciende los terribles eventos históricos del pueblo judío y conforman, en común con la concepción cristiana de la caridad, el eje pri- 
mario de la acción social, las cuales a su vez, caridad y benevolencia, como es sabido, se constituyen en la base del Trabajo Social preprofesional. Jeanne E. Abrams (2006) reúne con acierto las diferentes opiniones que enfrentan a los historiadores sobre los matices semánticos que distinguen estas primarias formas de acción social imbuidas por principios religiosos de origen común, pero diverso al mismo tiempo.

Un número de historiadores ha especulado sobre las diferentes motivaciones subyacentes en la naturaleza de la pobreza y de la caridad entre judíos, católicos y protestantes (...). Uno de los estudiosos resume el tópico del modo siguiente: la caridad protestante enfatiza el peligro de la indolencia y del despilfarro; la caridad católica se centra en las buenas obras como forma específica de gracia para el alma caritativa, pero la caridad judía valora al alegre donante discreto que respeta la dignidad del pobre (p. 95).

En una de sus intervenciones en público Norman Linzer (2013) afirmó:

En una comunicación de hace varios años sobre voluntariado en la tradición judía, comparé el voluntariado con el enfoque judío de la «hesed», el cual es definido como los actos de fraternidad de una persona hacia otra (...). La analogía con el trabajo social es clara. El trabajador social se ve envuelto en una variedad de situaciones que requieren sentimientos de compasión hacia el cliente (usuario), pero también requiere de habilidades ciertas en comprensión e intervención (...) idealmente, el trabajador social debería compartir estos sentimientos no sólo como requisito para una ayuda efectiva, sino porque emana de su humanidad y de su sensibilidad hacia las necesidades del otro.

Si importantes son las fuentes de las que brota la acción social solidaria, no menos relevantes son las cualidades necesarias para la intervención (profesional): el training o la experiencia de la que tanto hablamos en la práctica.
Cualidades que igualmente son importadas, quizá inconsciente pero felizmente, de una forma de ser y de un estilo de vida. En opinión del mismo autor, la autodisciplina, la contención, el control consciente son rasgos que definen al profesional del Trabajo Social general y que los profesionales judíos pusieron en común en el debate sobre las cualidades que debe poseer un profesional de la intervención.

De igual modo, uno de los requisitos ineludibles de una correcta acción profesional pivota sobre el sacrosanto principio de la confidencialidad de la intervención. Este principio de la confidencialidad en la relación profesionalusuario (o cliente) también procede de una estricta observancia religiosa. Fue Moshé ben Maimón, en sus «Ocho Grados de la Caridad» de su obra, Yad Hazakah, quien explica claramente, a modo de instrucciones, la necesidad imperiosa de preservar el anonimato de quien requiere o solicita el auxilio ${ }^{3}$. Señal inequívoca de atención para evitar, lo que en nuestro medio llamamos, la estigmatización.

Es admitido, y por todos conocidos, que el Trabajo Social se originó bajo la influencia determinante de tradiciones e inspiraciones religiosas. Sobre este punto, Edward R. Canda (1988) nos recuerda cómo «los escritos judíos y la ley religiosa (halakhah ${ }^{4}$ ) han motivado actividades de acción social durante siglos» (p. 30). Si bien, y como es lógico, nuestra perspectiva, más continental que anglosajona, concedió el protagonismo a la confesión dominante (a pesar de la multiplicidad de sus corrientes), la cual, por el devenir histórico, eclipsó las decisivas aportaciones de esta histórica minoría social. Sólo un país, como los Estados Unidos, con sus condicionantes históricos, su desarrollo económico-social, su apuesta decidida por un sistema político libre y plural, con una base étnica y religiosa muy amplia y diversa podía permitir, desde su diversidad social reconoci$\mathrm{da}$, el espacio de legitimidad necesario para la expansión y expresión de la identidad judía.

\footnotetext{
3 «Maimónides establece diez escalas de caridad. La más elevada es cuando se ayuda a un hombre a ayudarse a sí mismo, la cual debe conducir a su rehabilitación». En opinión de Newman y Siván (1983), «la tzedaká (justicia), debe preservar el carácter anónimo del dador» (p. 327).

${ }^{4}$ La Halahhah se conoce comúnmente como la Ley Judía, que marca los preceptos que deben regir un correcto estilo de vida de una persona judía desde un punto de vista religioso. Este estilo de vida influye y determina muchos aspectos de la cotidianidad. Una ilustrativa aproximación puede encontrarse en la obra de Wouk (2006).
} 
Los Estados Unidos son sobresalientes - como se recoge con sumo acierto en la obra conjunta de Terry Tirrito y Toni Cascio (2003) no sólo por sus elevados niveles de religiosidad, sino también por la variedad de sus religiones. La evolución del Trabajo Social americano es inexplicable sin su influencia, en particular del judaísmo y de las variantes cristianas. Gracias a esta libertad religiosa, muchas religiones han prosperado allí como en ningún otro lugar del mundo. $\mathrm{Y}$, se añade con precisión: la historia de las religiones en los EEUU es la historia de la inmigración (p. 138). Sobre este punto, y con mayor énfasis, el reconocido historiador a nivel internacional Paul Johnson (2006) afirma: «por primera vez desde la antigüedad, los judíos pudieron desplegar, para beneficio de la sociedad general, la capacidad legisladora creativa que había afinado durante tanto tiempo en el marco de la tradición rabínica» (p. 676).

\section{Personas, hechos y testimonios. La acción social judía en el germen del Trabajo Social} Los primeros hallazgos que se conocen en los Estados Unidos sobre servicios sociales judíos y para judíos datan de 1654 cuando se asienta la primera colonia en New Amsterdam, más tarde Nueva York ${ }^{5}$. Estos servicios iniciales de base comunitaria y filantrópica experimentan su posterior desarrollo y expansión con la llegada de numerosas oleadas de inmigrantes. $\mathrm{La}$ industrialización y la emergencia de núcleos urbanos en constante crecimiento, como es sabido, propiciaron la secularización y las iniciales motivaciones religiosas fueron reemplazadas paulatinamente por las nuevas doctrinas fundamentadas en el derecho natural, dando lugar a la fundación de la primera escuela de Trabajo Social en los Estados Unidos, en la ciudad de Nueva York bajo los auspicios de la Charity Organization Society, «por lo que puede afirmarse que el Trabajo Social judío nació al mismo tiempo que el Trabajo Social profesional» (Goldsmith, Scult y Seltzer, 1990, p. 358).
Con el fin de planificar y coordinar las distintas agencias judías, un paso decisivo se realizó en 1908 con la fundación de la National Association of Jewish Social Work, nueve años antes de la creación de la American Association of Social Workers (AASW). Consolidándose de este modo el fin del amauterismo filantrópico confesional y el inicio de la profesionalización. Si bien, la dispersión de las diferentes agrupaciones de profesionales continuará hasta 1955 , fecha en la que al fin se agruparán bajo la denominación de National Association of Social Workers.

No sin razón, la National Association sostiene que Baltimore, ciudad multirracial y multirreligiosa, y sede del prestigioso centro universitario John Hopkings University, es, en cierto modo, la cuna del Trabajo Social profesional. Y no sólo por Mary Richmond, sino también por Amos Griswold Warner cuyo libro, Caridad americana, se convirtió posteriormente en uno de los manuales básicos de las escuelas de Trabajo Social de la época; Daniel Coit Gilman, Presidente de la Charity Organization Society (COS); Anite Rose Williams, primera supervisora afroamericana empleada en una agencia social, etc.; pero también por trabajadores sociales judíos, entre ellos, Louis Hiram Levin, secretario de la Conferencia Nacional de los trabajadores sociales judíos, o Esther Lazarus que en 1952 se convirtió en la primera mujer directora de los servicios sociales de un centro urbano.

Especial mención merece Henrietta Szold, nacida también en Baltimore en 1860, hija del rabino Benjamin Szold, que llegó a convertirse en reconocida pionera del Trabajo Social en Israel, cuyo primer proyecto de la organización Hadassah $^{6}$, relacionado con la asistencia para cuidados sanitarios a domicilio, se ganó los elogios de Jane Addams. Es preciso recordar además que simultáneamente al proceso de configuración del Trabajo Social, como profesión y disciplina, la batalla por la modernización en pro de una intervención más «profesional», basada en criterios científicos, también

\footnotetext{
${ }^{5}$ Para estos inicios históricos, puede consultarse, entre otras, la interesante exposición de S. Imber (1990).

${ }^{6}$ Hadassah, fundada por Enrietta Szold en 1912, fue la organización femenina sionista de América. Bajo su dirección se organizó un sistema de visitas de enfermeras norteamericanas a Palestina, dadas las condiciones precarias de salud de la población judía y no judía.
} 
estaba en juego el proceso de conquista de libertades en aras de la igualdad de género, cuyo objetivo más anhelado no era sólo la adquisición del sufragio universal, sino también del reconocimiento social, profesional y académico de la mujer. También político. El énfasis de Hadassah en esfuerzos prácticos enraizaba con las iniciativas del trabajo social de Jane Addams, Lillian Wald y otras progresistas americanas que a menudo mostraban su desacuerdo con los varones sionistas imbuidos por la retórica nacionalista y que aborrecían los viejos modelos de caridad para los judíos en Palestina, (McCune, 1998).

Junto a ellas, otras muchas mujeres judías, que destacaron no sólo por su labor social, sino también por su participación activa en los foros de la época sobre la cuestión incipiente en torno a la identidad del Trabajo Social general, como: Rebecca Gratz, Clara Dercum, Mary Cohen, Helen Kirshbaum, Sarah Vasen, Anna Broomal, Eleanor Jones, etc.

Aún más: no puede obviarse tampoco el duelo intelectual entre Mary Richmond y Abraham Flexner, autoridad líder en el país en formación profesional (e hijo de padres inmigrantes judíos ortodoxos), con motivo, en 1915, del polémico discurso ${ }^{7}$ que Flexner lanzó en la celebración de la National Conference on Charities and Correction. El estímulo del debate abierto condujo, por ejemplo, en palabras de Agnew (2004), a que "Richmond, en su discurso de 1917 «The Social Case Worker's Task» reconociera que Flexer estaba en lo cierto al considerar a los trabajadores sociales como «intermediarios sociales»(p. 166). Este debate profundo sobre la identidad de una profesión en emergencia permitió, sin duda, todo un flujo de ideas, comentarios y argumentaciones que enriquecieron y fortalecieron el proceso intelectual de la formación de su cuerpo teórico.

\section{El New Deal y la emergencia de la res- ponsabilidad pública. El comienzo del fin del Trabajo Social judío}

La Gran Depresión produjo un efecto político completamente transformador en suelo ameri- cano: la creación del Estado de bienestar. La emergencia de los nuevos servicios sociales de naturaleza pública implicará una nueva concepción del Trabajo Social, especialmente de la mano de nuevos tipos de usuarios (Reisch, 1998). Esta irrupción de un intensivo intervencionismo público en los asuntos sociales puso en cuestionamiento la concepción tradicional del fenómeno de la pobreza. De ahí que la crisis económica, señala Toni Cascio (1996), entre otras consecuencias, influyera en que,

El flujo de los refugiados alemanes colocaron a los judíos americanos en una posición muy diferente de los otros grupos religiosos y étnicos (...). El resurgimiento de las actividades del Ku Klux Klan se había reiniciado poco antes de la Gran Depresión a mediados de los años 20, para los cuales los judíos eran considerados tanto comunistas como plutócratas (p. 220).

Esta situación conllevó que la gran mayoría de los americanos en general, y de los judíos americanos en particular, apoyara abiertamente el intervencionismo público. Un apoyo que no estuvo exento de la polémica conocida, en torno a la cuestión de la especificidad o singularidad del Trabajo Social judío. Advertía el director de la Graduate School for Jewish Social Work, M. J. Karpf (1934):

Como trabajadores sociales judíos tendréis un número de desafíos adicionales. Oiréis que el trabajo social judío está desapareciendo (...). Que el creciente trabajo social público está rápidamente tomando su lugar (...) que no hay más necesidad de un trabajo social judío específico (...) [Insto] a los trabajadores sociales a repudiar, en términos inequívocos, sobre lo que se está haciendo en nombre del trabajo social (p. 194).

En la misma línea argumental, aunque en términos más severos, David G. Dallin (1997) comenta:

La Gran Depresión y el New Deal presentó la primera seria amenaza al principio de la autosuficiencia de la comunidad (...). [y concluye] El abrazo continuo de los liberales judíos a los principios y programas de del Estado de bienestar representa una profunda y radical separación

\footnotetext{
7 Para acceder al texto íntegro de la publicación presentada por Abraham Flexner, titulado Is Social Work a Profession? (1915), puede consultarse el siguiente enlace de la Cornell University Library: http://archive.org/details/cu31924014006617.
} 
de siglos de tradición judía, y un repudio a los principios comunitarios y religiosos duraderos sobre los cuales esta tradición se ha basado tanto tiempo (p. 33).

Esta batalla de laicismo versus religiosidad de la acción social impregnó igualmente a todas las confesiones religiosas, si bien en los ámbitos judíos la escisión fue más incisiva ${ }^{8}$. El resultado final lo certifica nítidamente J. Fisher (1980) al afirmar que, en 1932, el 80 por ciento de las familias americanas en situación de necesidad eran ya atendidas por los servicios públicos. En los medios judíos, destacan numerosos trabajadores sociales en defensa de la responsabilidad pública, entre los cuales pueden destacarse: Solomon Lowenstein, director de la Federation of Jewish Philanthropies de Nueva York; Jacob Billikopf de la Philadelphia Federation of Jewish Charities; Frances Taussing director de la Jewish Social Service Association of Social Workers; y Harry Greenstein de la $A s$ sociated Jewish Charities de Baltimore, entre otros. La crisis económica, apunta Beth S. Wenger (1996), fue uno de los factores que, sin duda, impulsó este cambio de postura. «La depresión no sólo frustró las ambiciones personales de los judíos americanos, sino que también desestabilizó las bases de la vida comunal, las instituciones judías cayeron en el umbral de la bancarrota y del colapso» (p. 159).

El periodo de entreguerras, la crisis económica, el ascenso del nazismo, el desenlace de la II Guerra Mundial y la llegada de nuevos refugiados que huían del terror en Europa pusieron en trance el modelo de satisfacción de las necesidades en el seno de las comunidades judías y revolucionaron la forma no sólo de entender la intervención profesional, con la introducción en la práctica de las teorías procedentes de la psicología y el psicoanálisis, sino también de parte de los fundamentos éticos.

La experiencia de la Shoá marca un antes y un después en la historia de la civilización occidental, y como es lógico también en el uni- verso del pensamiento y de la ética judía y universal. La influencia de Emmanuel Lévinas, uno de los grandes filósofos del siglo XX, a nivel mundial es incuestionable, y su contribución intelectual ha orillado en la deontología de todas las profesiones. La ética profesional es la esencia que debe guiar las intervenciones profesionales. La presencia del judaísmo en su reflexión filosófica es incontestable. De las raíces judías de su humanismo y la experiencia en carne propia $^{9}$ de los campos de la II Guerra Mundial brota su concepción particular de la alteridad. Como señala certeramente IdaretaGoldaracena (2010, 2011):

La ética de Lévinas siempre nos lleva más allá de lo que hacen los códigos deontológicos (...) nos insta siempre a ir más allá de lo establecido por aquel marco de referencia moral que nos anquilosa en la obediencia ciega a sus principios, promoviendo aquella sensibilidad y vigilancia para con el usuario por las que no podamos dejar de responder ante su sufrimiento como compasión responsable para con él (2010, p. 72$)^{10}$.

\section{Conclusiones}

En estas páginas se ha intentado poner de manifiesto que en el origen y evolución del proceso de desarrollo del Trabajo Social, como profesión y disciplina, destacados pioneros judíos desempeñaron un papel transcendental. La experiencia de la actividad ancestral de intervenir (empoderando) en grupos y comunidades por razones puramente religiosas, pero sin duda también por motivos sociales y, especialmente, políticos enraíza con los orígenes del Trabajo Social pre-profesional y posterior. Como grupo social distinguido, perseguido a lo largo de toda la historia, el pueblo judío, a pesar de las dificultades y vicisitudes y cuando las circunstancias históricas lo han permitido, ha desplegado su creatividad extraordinaria y ha formado parte de los procesos de construcción. En el campo de las ciencias y de las artes, era cono-

8 Para mayor información, puede consultarse, entre otras recomendaciones, las lecturas de Reisma, (1981) y Jick (1999).

9 El autor, por su condición de judío, estuvo prisionero en los campos entre Bremen y Hannover. Toda su familia de Lituania fue aniquilada en Auschwitz. Tras su vuelta a Francia, retoma su actividad a favor del judaísmo y dirige la Alianza Israelita Universal, desde 1946 hasta 1961.

10 También del mismo autor, y en los que incisivamente se hace auténtica cirugía del pensamiento filosófico-humanista de Lévinas, son de valor las siguientes consultas (2012) y (2013). 
cida su contribución muy estimable, en menor medida en el campo de lo social, tradicionalmente concebido entre los guetos sociales y económicos que amurallaban su participación por la imposición de la cultura dominante. La influencia del pensamiento humanista, su concepción filosófico-religiosa de la existencia, sus valores éticos de solidaridad y justicia, su capacidad organizativa, su naturaleza singular para articular toda una arquitectura del método para el debate, el intercambio y la comunicación en el amplísimo mundo de las Ideas, son determinantes para la comprensión exhaustiva del proceso histórico.

La experiencia práctica, por un lado, y la transmisión e intercambios de saberes en los foros y debates de la época, por el otro, entre los profesionales de la intervención social y de la enseñanza, muchos de los cuales llegaron, incluso, a desempeñar puestos de responsabilidad en agencias públicas, como Esther Lazarus o Abraham Flexner, entre otros, permiten concluir que una parte se debe a la aportación de lo que se denominaba entonces «Trabajo Social judío». Esta contribución, lejos de restar importancia a las otras confesiones religiosas y a los reformistas, varones y mujeres, de cualquier otro credo, suma y enriquece la confluencia de elementos explicativos que permiten entender el origen y desarrollo del Trabajo Social pre-profesional.

Por lo tanto, el Trabajo Social posee también un origen judío, pero su elemento sobresaliente no reside tanto en la génesis como en su desarrollo ulterior. La cuna anglosajona de nuestra disciplina es incuestionable, pero también lo es que la influencia del judaísmo imprimió igualmente parte de su propia identidad.

\section{Referencias bibliográficas}

Abramovitz, M. (1998). Regulating the Lives of Women: Social Welfare Policy from Colonial Times to the Present. ( $2^{\mathrm{a}}$ Edición). Boston: South End Press.

Abrams, J. (2006). Jewish Women Pionering. The frontier trail. A history in the American West. Nueva York: University Press.

Agnew, E. (2004). From Charity to Social Work. Mary E. Richmond and the Creation of an American Profession. Illinois: University Press.

Axinn, J. y Stern, M. (2001). Social Welfare: A History of the American Response to Need. (5 Edición). Boston: Allyn and Bacon.

Canda, E. (1998). Conceptualizing Spirituality for Social Work: Insights from Diverse Perspectives. Journal of Religion \& Spirituality in Social Work: Social Thought, 14 (1), 30-46.

Cascio, T. (1996). At a Crossroads, Jewish Social Services and the Great Depression. Journal of Jewish Communal Service, 72 (3), 217-223.

Dallin, D. (1997). Judaism's War on Poverty. Policy Review, 85, 29-33.

Fisher, J. (1980). The response of Social Work to the Depression. Cambridge: Schenckman.

Goldsmith, E., Scult, M. y Seltzer, R. (1990). The American Judaism of Mordecai M. Kaplan. Nueva York: New York University Press.

Healy, L. (2001). International Social Work. Professional Action in an Interdependent World. Oxford: Oxford University Press.

Idareta Goldaracena, F. (2010). Desde la compasión de J. Addams a la responsabilidad para con el Otro: la propuesta ética de E. Lévinas para el Trabajo Social. Portularia, X (2), 65-75.

Imber, S. (1990). Serving non-jews in the Jewish Family Agency. Journal of Jewish Communal Service, 66 (4), 382-386.

Ivers, C. (1995). To Build a wall. American Jews and the separation of church and state. Constitutionalism/Democracy Series. Virginia: The University Press of Virginia.

Jick, L. (1999). The transformation of Jewish Social Work. Bernard Reisman and the Hornstein Program at Brandeis University. Journal of Jewish Communal Service, 75 (2/3), 114-120.

Johnson, P. (2006). La historia de los judios. Barcelona: Ediciones B.S.A.

Karpf, M. (1934). Toward a Philosphy for the Jewish Social Work. The Jewish Social Service Quartely, XI (2), 193-194.

Leiby, J. (1979). A History of Social Welfare and Social Work in the United States. Nueva York: Columbia University Press. 
Linzer, N. (1978). A Jewish Philosophy of Social Work Practice. Nueva York: Yeshiva University, New York. Recuperado de: http://www.policyarchive.org/handle/10207/bitstreams/16834.pdf (Consultado el 6 de junio de 2013).

Lubove, R. (1965). The Professional Altruist: The Emergence of Social Work as a Career, 18901930. Cambridge, MA: Harvard University Press.

Lyons, K., Hokenstad, T., Pawar, M., Huegler, N. y Hallet, N. (eds.) (2012). The sage handbook of International Social Work. Londres: Sage Publications Ldt.

Marcus, J. (1981). The American Jewish Women, 1654-1980. Jersery: Ktav Publishing House, Inc.

McCune, M. (1998). Social Workers in the Muskeljudentum: «Hasassah Ladies», «Manly Men» and the significance of Gender in the American Zionist Movement, 1912-1928. American Jewish History, 86 (2), 135-165.

Méndez-Bonito, P. (2011). Reflexiones sobre la estructura ética del pensamiento de Mary Richmond. Cuadernos de Trabajo Social, 24, 23-33.

Newman, J. y Siván, G. (1983). Judaísmo A-Z. Léxico Ilustrado de Términos y Conceptos. Jerusalén: Prensa Astronel, Departamento de Educación y Cultura Religiosa para la Diáspora de la Organización Sionista Mundial.

Reisch, M. (1998). The Sociopolitical Context and Social Work Method, 1890-1950. The Social Service Review, 72 (2), 161-181.

Reisma, B. (1981). The Jewish Component in the Training Programs of Jewish Communal Workers. Journal of Jewish Communal Service, 58(2), 95-102.

Simon, B. (1994). The Empowerment Tradition in American Social Work: A History, Nueva York: Columbia University Press.

Stein, H. (1958). Jewish Social Work in the United States 1654-1954, (Tesis doctoral. Columbia University: American Jewish Year Book.

Tirrito, T. y Cascio, T. (eds.) (2003). Religious Organizations in Community Services. A Social Work Perspective. Nueva York: Springer Publishing Company.

Wenger, B. (1996). New York Jews and The Great Depression. Uncertain Promise. Yale: University Press.

Wouk, H. (2006). Éste es mi Dios. El estilo de vida judio. Barcelona: Riopiedras Ediciones.

Zastrow, C. (2010). Introduction to Social Work and Social Welfare. Empowering People. Belmont: Brooks/Cole, Cengage Learning.

Zelditch, M. (1947). Social action in Jewish Social Work. The Jewish Social Service Quartely, $24,(1), 16-20$. 